\title{
Una reflexión sobre los «nuevos» derechos. Perspectivas y desafíos en el siglo XXI
}

\author{
A reflection upon the «new» rights. prospects and \\ challenges in the 21st Century
}

\author{
GABRIELA FAUTH \& \\ PAOLA MILENKA VILLAVICENCIO CALZADILLA*
}

\begin{abstract}
Resumen: El presente trabajo pretende analizar el cambio de paradigmas derivado del proceso de transición de la Modernidad hasta la Posmodernidad y los desafíos enfrentados hoy en el campo jurídico. Asimismo, el objetivo es reflexionar sobre los llamados «nuevos» derechos, enfocados a partir del derecho ambiental y del derecho urbanístico, considerados los precursores de esta perspectiva en el Derecho posmoderno y, por fin, presentar los desafíos y las perspectivas de su consumación en el siglo XXI.
\end{abstract}

Palabras clave: Posmodernidad - «nuevos» derechos - siglo XXI

Summary: This paper analyses the paradigm shift that comes from the transition from Modernity to postmodernity process and the challenges faced today in the legal field. Furthermore, the aim is to reflect upon the so-called «new» rights, focusing on the environmental law and urban planning law, considered the precursors of this postmodern perspective on the law. Finally, it presents its challenges and prospects for the 21st Century.

Key words: Postmodernity - «new» rights -21 st Century

CONTENIDO: I. INTRODUCCIÓN.- II. LOS «NUEVOS»DERECHOS COMO CAMBIO DE PARADIGMA EN LA TRANSICIÓN A LA POSMODERNIDAD.III. DESAFÍOS Y PERSPECTIVAS DEL DERECHO EN EL CONTEXTO DEL SIGLO XXI.- IV. CONSIDERACIONES FINALES.

\section{INTRODUCCIÓN}

El presente artículo es un breve estudio sobre los nuevos paradigmas del derecho ante los desafíos de la posmodernidad ${ }^{1}$. En este contexto,

* Es becaria predoctoral del Departament de Dret Públic de la Universitat Rovira i Virgili (URV), vinculada al Centre d'Estudis de Dret Ambiental de Tarragona (CEDAT), Tarragona, España. Correo electrónico: gabriela.fauth@urv.cat. Paola Milenka Villavicencio Calzadilla es becaria predoctoral del Departament de Dret Públic de la Universitat Rovira i Virgili (URV), vinculada al Centre d'Estudis de Dret Ambiental de Tarragona (CEDAT), Tarragona, España. Correo electrónico: p_villavicencio@ hotmail.com

1 Según Bittar, la expresión postmodernidad denomina un contexto sociohistórico particular, que se funda en la base de reflexiones críticas sobre el agotamiento de los paradigmas instituidos y construidos por la modernidad occidental (ver BITTAR, Eduardo Carlos Bianca. "O direito na pós-modernidade». Revista Seqüência, 57 (2008), pp. 131-152, p. 132). Se trata de una época que "Anthony Giddens Ilama "modernidad tardía"; Ulrich Beck, "modernidad reflexiva"; Georges Balandier, "supermodernidad", y que yo prefiero (al igual que muchos otros) llamar posmoderna" 
se analiza los conflictos urbano-ambientales, enfocando las cuestiones emergentes de la sociedad contemporánea. Por tanto, se trata de un análisis bajo la perspectiva de los «nuevos» derechos ${ }^{2}$, es decir, del rompimiento de los paradigmas de la modernidad en su transición hacia la posmodernidad, considerando las nuevas demandas que surgen, adaptadas a los también nuevos actores sociales. Siendo así, lo que se interpreta como nuevo en el derecho es la «desprivatización» de intereses, eso significa que se introduce en una configuración de intereses y derechos difusos y colectivos. Esto desconecta al derecho de la idea individualista traída por la Revolución Francesa de 1789 y desarrollada durante el Modernismo ${ }^{3}$. Sin embargo, como comenta Bittar:

Los conflictos dejan de tener la proporción y la perspectiva de conflictos individuales y pasan a ser conflictos coyunturales, colectivos, asociativos, difusos, transindividuales, motivando el colapso de las formas tradicionales de atender las demandas para las cuales solamente se conocían mecanismos típicos del Estado liberal, estructurado sobre las categorías del individuo y del burgués ${ }^{4}$.

En razón de esta contextualización se abordará la tutela del derecho ambiental y del derecho urbanístico, su surgimiento ante esta revisión de paradigmas oriundos de herencias modernas y cómo ocurre esta transición en el sistema jurídico — aún en fase de conformación-. Igualmente, se analizará los desafíos y las perspectivas de su aplicación en la coyuntura del siglo XXI, ya que estas dos áreas del derecho son consideradas precedentes, pero aún carecen de adecuación en relación con las actuales demandas. No obstante, pueden ser consideradas nuevas fronteras en el cerrado sistema jurídico proveniente del siglo XVIII y se revelan como alternativa de cambio de las estructuras jurídicas tradicionales y de las prácticas sociales instituidas. Esta alternativa tiende a suscitar un proyecto social que posibilite que el derecho sea eficaz en su tutela de control social, adaptado a la actualidad, especialmente en una perspectiva de impactos ambientales y de la sociedad del riesgo.

(BAUMAN, Zygmunt. O mal-estar da pós-modernidade. Río de Janeiro: Zahar, 1998, p. 30; citado en BITTAR, Eduardo Carlos Bianca. Ob. cit., p. 132). Siguiendo a Bauman, este trabajo empleará el término posmodernidad.

2 Ver LeITE, José Rubens Morato \& Antonio Carlos WolkMER (orgs.). Os «novos» direitos no Brasil. Natureza e perspectivas: uma visão básica das novas conflituosidades jurídicas. São Paulo: Saraiva, 2003.

3 Aquí cabe recordar que existe una contradicción, ya que el hombre posmoderno también está caracterizado por el individualismo, además de por el consumo y por el riesgo. Según Santos, "O pós-modernismo é um fantasma que passeia por castelos modernos" (SANTOS, Boaventura de Sousa. Pela mão de Alice: o social e o político na pós-modernidade. Octava edición. Porto: Afrontamento, 2002, p. 18). Para el autor, este fantasma rodea entre la humanidad desde la década de 1980. Del mismo modo, Bittar atesta que se debe observar que las relaciones entre modernidad y posmodernidad son ambiguas, existen más aspectos en común que divergencias (ob. cit., p. 133). El individualismo actual, por ejemplo, nació con la modernidad, con la Revolución francesa, pero su narcisista exageración fue añadida por la posmodernidad.

4 BITTAR, Eduardo Carlos Bianca. Ob. cit., pp. 143-144. 
A continuación, a partir de este contexto, se examinará la tutela de los derechos difusos y colectivos como consolidación de los «nuevos» derechos.

\section{LOS «NUEVOS» DERECHOS COMO CAMBIO DE PARADIGMA EN LA TRANSICIÓN A LA POSMODERNIDAD} La sociedad contemporánea, posmoderna, se caracteriza por la pérdida de conceptos. Esto lleva a que todo sea considerado incierto, dudoso. Según Bauman ${ }^{5}$, los conceptos tienen en la posmodernidad un «carácter liquido». En el caso del derecho, esta incertidumbre aflora, principalmente, a través de una crisis ambiental, la llamada crisis de la modernidad. Esta crisis surge por la transición de la modernidad a la posmodernidad, caracterizada por el quiebre de paradigmas y por el inicio de un nuevo periodo, hoy llamado «sociedad del riesgo». La sociedad del riesgo es considerada el período en que el hombre no puede controlar de forma segura su relación con su entorno, sea ambiental, social, económico, cultural, etcétera. Por tanto, la principal característica del hombre posmoderno en la sociedad del riesgo es su vulnerabilidad.

La sociedad contemporánea produce riesgos que pueden ser controlados y otros que escapan o neutralizan los mecanismos de control típicos de la sociedad industrial ${ }^{6}$. De este modo, la sociedad del riesgo se presenta como un modelo teórico que marca la falencia de la modernidad. Se trata de una crisis de paradigma, una crisis de la modernidad. En este caso, como comentan Leite y Belchior ${ }^{7}$, se emerge a un período posmoderno, en la medida en que las amenazas producidas a lo largo de la sociedad industrial empiezan a tomar forma. Para Beck ${ }^{8}$, el momento actual representa la llamada era de la modernidad reflexiva (o posmodernidad), la cual, por definición, ya es una sociedad del riesgo. Esto se debe a que el autor sistematiza los riesgos como formas de tratar los peligros y las inseguridades introducidas por el proceso de modernización.

Otra característica de la posmodernidad es el advenimiento de la globalización, lo cual pone a prueba el ideal jurídico y su capacidad funcional en la sociedad actual. A propósito:

las transformaciones sociales, políticas, económicas y culturales han venido a exigir una nueva reflexión sobre los problemas centrales de la Teoría General del Derecho, desde el de los modelos jurídicos o el de los métodos hermenéuticos y las fuentes, hasta el

5 Ver BAUMAN, Zygmunt. Ob. cit.

6 LEITE, José Rubens Morato \& Germana Parente Neiva BELCHIOR. «O Estado de Direito Ambiental e a articularidade de uma hermenêutica jurídica». Revista Seqüência, 60 (2010), pp. 291-318, p. 293.

7 Ver ibídem.

8 Ver BECK, Ulrich. La sociedad del riesgo. Buenos Aires: Paidós, 1998, p. 199.

UNA REFLEXIÓN

SOBRE LOS

«NUEVOS»

DERECHOS.

PERSPECTIVAS Y DESAFÍOS EN EL

SIGLO XXI

A REFLECTION

UPONTHE

«NEW» RIGHTS.

PROSPECTS

AND CHALLENGES

IN THE

21ST CENTURY 
de la integración del ordenamiento y las relaciones entre legalidad y legitimidad 9 .

Teniendo en cuenta la afirmación anterior, es correcto afirmar que el derecho ambiental y el derecho urbanístico ${ }^{10}$ no pueden ser interpretados como un precepto formal originario de un orden jurídico clásico, articulados entre el derecho civil y el derecho administrativo, por ejemplo. Su práctica requiere adaptación a los litigios actuales, a fin de que operen a favor de la nueva dinámica jurídica en el sentido de satisfacer las reivindicaciones de la sociedad caracterizada, principalmente, por la vulnerabilidad socio-ambiental.

«La sociedad posmoderna vive la lógica del tiempo imperioso y del riesgo, donde la sociedad se caracteriza por estar fragmentada y ser diferenciada, aumentando el grado de complejidad del sistema social $»^{11}$. Según Leite y Beclhior ${ }^{12}$, este contexto invoca nuevas herramientas jurídicas, así como otras técnicas hermenéuticas de colisión entre los derechos fundamentales y, según los autores, los principios, de ponderación (bienes, valores e intereses) y de proporcionalidad (medios y medidas), a fin de buscar, mediante el equilibro, la protección jurídica correspondiente.

A partir del derecho ambiental y del derecho urbanístico se vislumbra nuevos contornos en el campo del derecho. Contorno que posibilitan un reconocimiento social y una dinámica transformadora en un nuevo orden jurídico. Para Marshall ${ }^{13}$, el derecho evoluciona de manera lineal y acumulativa, a través de «generaciones» de derechos ${ }^{14}$. Esta periodización se concreta a través de épocas: en el siglo XVIII nacen los derechos civiles; en el siglo XIX se consagran los derechos políticos; a mediados del siglo XX se consolidan los derechos sociales. La tercera «generación» de derechos es justamente la que contempla los derechos que vienen a corroborar toda la teoría de los «nuevos» derechos, interpretados como derechos transindividuales. Según Leite y Wolkmer ${ }^{15}$, precisamente es en este grupo que se encuentran los derechos metaindividuales, colectivos o difusos, de modo que el principal cambio que los caracterizaría es que no es más el hombre en su individualidad el titular de los derechos. Pero, ellos tampoco regulan las relaciones entre los individuos y el Estado, sino que prevalece una protección de las categorías o de los grupos de

9 FARIA, José Eduardo. El derecho en la economía globalizada. Madrid: Trotta, 2001, p. 106. La traducción es nuestra.

10 Objetos de estudio de este trabajo.

11 BAGGIO, Andreza Cristina. "A sociedade de risco e a confiança nas relações de consumo». Revista de Direito Econômico e Socioambiental, I, 1 (2010), pp. 127-147, p. 132.

12 LEITE, José Rubens Morato \& Germana Parente Neiva BELCHIOR. Ob. cit., pp. 310-311.

13 MARSHALL, . Citado en LeITE, José Rubens Morato \& Antonio Carlos WolKMER (orgs.). Ob. cit., p. 5.

14 Actualmente hay una discusión importante sobre cuál es el término más correcto: «generaciones» o "dimensiones» de derechos. Pero en este trabajo no se analizará dicha discusión y se utilizará indistintamente los dos vocablos «generación» y «dimensión».

15 LeITE, José Rubens Morato \& Antonio Carlos Wolkmer (orgs.). Ob. cit., p. 5. 
personas (familia, pueblo, nación). Su categorización no se ajusta al ámbito público y, tampoco, al privado ${ }^{16}$.

Para Sauwen y Hryniewicz ${ }^{17}$, los derechos metaindividuales se caracterizan por no fraccionar los derechos. La satisfacción o lesión del interés no se puede dar de modo fraccionado solo para uno o algunos interesados. Por otro lado, los derechos difusos se centran en realidades fácticas que generan satisfacción común a todos, como personas anónimas involucradas en un mismo hecho o que viven en la misma localidad, por ejemplo. Mientras que los derechos colectivos se refieren a los intereses comunes de personas conectadas por organizaciones sociales, sindicatos o asociaciones profesionales, etcétera.

Para Antunes ${ }^{18}$, los intereses difusos son los que tienen como una de sus características la privación de su titular específico, por tanto, estos son sustancialmente «anónimos». En consecuencia, cuando se trata de intereses difusos, no es posible precisar jurídicamente quiénes son las víctimas, si no se sabe que versa sobre una pluralidad de sujetos, si bien indeterminables, como toda una comunidad específica. Es notorio que la dimensión es colectiva, pero los interesados pueden ser personas conectadas por alguna circunstancia común, aunque el interés acabe condicionando a los demás ciudadanos a beneficiarse, lo cual da lugar a una satisfacción colectiva.

Además de todo lo expuesto, queda claro que los «nuevos» derechos nacen a razón de la tercera «dimensión» de derechos, aquella que interpreta el derecho de forma transindividual. asimismo, pertenecen a este concepto los derechos metaindividuales, colectivos y difusos. Mas queda evidenciado que independientemente de a cuál de estos tres conceptos del derecho se refiera, lo «nuevo» en el derecho implica «desprivatizar intereses», lo cual lo introduce en una perspectiva colectiva.

Finalmente, el derecho pasa por cambios tan dinámicos como la sociedad en que él mismo está inserido, es decir, se encuentra en un proceso continuo. Por tanto, cabe a sus operadores atender e instrumentalizar estas nuevas demandas.

UNA REFLEXIÓN

SOBRE LOS

«NUEVOS»

DERECHOS.

PERSPECTIVASY

DESAFÍOS EN EL

SIGLO XXI

A REFLECTION

UPONTHE

«NEW» RIGHTS.

PROSPECTS

AND CHALLENGES

IN THE

21ST CENTURY 


\section{DESAFÍOS Y PERSPECTIVAS DEL DERECHO EN EL CONTEXTO DEL SIGLO XXI}

Para Duailibe y Belchior «as incertezas científicas e a liquidez dos conceitos penetram diretamente na problemática ecológica, invadindo, inclusive, o próprio conceito de bem ambiental e as bases teóricas do Estado» ${ }^{19}$. Del mismo modo, en el contexto de la ciudadanía, lo que se ve es una generalización de modelos culturales o de sus referencias, además de una penetración en las especificidades y particularismos que conducen a la uniformización de los modelos ${ }^{20}$. En este sentido, es como consecuencia de la posmodernidad y de la incertidumbre o generalidad de los conceptos que se plantea la temática de los «nuevos» derechos. Esta incertidumbre o generalidad da lugar, desde la perspectiva de los impactos ambientales, al derecho ambiental; y, desde la perspectiva de los conflictos sociales inherentes a la ciudad, al derecho urbanístico, en su contexto más amplio al derecho a la ciudad ${ }^{21}$. Considerando que el medio ambiente urbano, asimismo, es escenario de los problemas ambientales del siglo XXI y que el derecho a la ciudad reivindica una ciudad sostenible ${ }^{22}$, justa, plural y democrática, las dos temáticas se yuxtaponen.

19 DUAILIBE, Erika Pereira \& Germana Parente Neiva BELCHIOR. «Pós-modernidade e Estado de Direito Ambiental: desafios e perspectivas do Direito Ambiental». Actas del XIX Encontro Nacional do CONPEDI. Fortaleza, junio de 2010, p. 1547.

20 SALGUEIRO, Teresa Barata. "Cidade pós-moderna: espaço fragmentado». Revista Território, CXI, 4 (1998), p. 43.

21 Contenido de la Carta Mundial por el Derecho a la Ciudad, presentada en el V Forum Social Mundial realizado en Porto Alegre en 2005: «El Derecho a la Ciudad es definido como el usufructo equitativo de las ciudades dentro de los principios de sustentabilidad, democracia, equidad y justicia social. Es un derecho colectivo de los habitantes de las ciudades, en especial de los grupos vulnerables y desfavorecidos, que les confiere legitimidad de acción y de organización, basado en sus usos y costumbres, con el objetivo de alcanzar el pleno ejercicio del derecho a la libre autodeterminación y un nivel de vida adecuado. El Derecho a la Ciudad es interdependiente de todos los derechos humanos internacionalmente reconocidos, concebidos integralmente, e incluye, por tanto, todos los derechos civiles, políticos, económicos, sociales, culturales y ambientales que ya están reglamentados en los tratados internacionales de derechos humanos.

Esto supone la inclusión de los derechos al trabajo en condiciones equitativas y satisfactorias; a fundar y afiliarse a sindicatos; a seguridad social, salud pública, agua potable, energía eléctrica, transporte público y otros servicios sociales; a alimentación, vestido y vivienda adecuada; a educación pública de calidad y la cultura; a la información, la participación política, la convivencia pacífica y el acceso a la justicia; a organizarse, reunirse y manifestarse. Incluye también el respeto a las minorías y la pluralidad étnica, racial, sexual y cultural y el respeto a los migrantes.

El territorio de las ciudades y su entorno rural es también espacio y lugar de ejercicio y cumplimiento de derechos colectivos como forma de asegurar la distribución y el disfrute equitativo, universal, justo, democrático y sustentable de los recursos, riquezas, servicios, bienes y oportunidades que brindan las ciudades. Por eso el Derecho a la Ciudad incluye también el derecho al desarrollo, a un medio ambiente sano, al disfrute y preservación de los recursos naturales, a la participación en la planificación y gestión urbana y a la herencia histórica y cultural».

Posteriormente a este evento, el Derecho a la Ciudad gana estatus internacional como derecho fundamental en la esfera del Derecho Internacional.

22 Sostenible desde un punto de vista global, en el sentido de satisfacer las necesidades ambientales y sociales; es decir, un territorio justo, plural y democrático. Cavallazzi afirma que la ciudad sostenible puede ser traducida por equidad. La autora tiene toda la razón, de modo que la búsqueda del desarrollo sostenible es justamente la búsqueda de la equidad social, económica y ambiental (ver CAVAlLaZZI, Rosângela Lunardelli. «O estatuto epistemológico do Direito Urbanístico Brasileiro: possibilidades e obstáculos na tutela do Direito à Cidade». En COUTINHO, Ronaldo \& Luigi BONIzZATO (orgs.). Direito da cidade: novas concepções sobre as relações jurídicas no espaço social urbano. Río de Janeiro: Lúmen Júris, 2007, pp. 53-69). 
Cuando se menciona la sostenibilidad se alude a un amplio concepto que comprende tanto nociones del derecho ambiental como del derecho urbanístico. Pero, además, se trata de tornar eficaz el Derecho a la ciudad, promoviendo el diálogo entre ambos derechos, puesto que la perspectiva jurídica urbano-ambiental es esencial para garantizar una ciudad sostenible. Así, el derecho a la ciudad pasa a ser un presupuesto de la sostenibilidad, un presupuesto del cumplimiento de las funciones sociales y ecológicas de la ciudad.

Si el derecho a la ciudad, hoy, puede ser considerado como un derecho humano que posiciona a los individuos sobre el territorio, a partir de esta distribución espacial se ejercerán todos los derechos sociales que componen su amplio concepto. Los referidos derechos sociales en la ciudad van más allá, pues, en realidad, son derechos difusos y colectivos articulados de manera tal que componen el derecho fundamental a la calidad de vida.

La tutela del derecho a la ciudad se da a través de la articulación del derecho con el urbanismo y del reconocimiento de los derechos transindividuales. Lo cual ocurre desde una perspectiva interdisciplinar y flexible, actualmente denominada «nuevos» derechos. En tal sentido, el derecho ambiental es merecedor de una hermenéutica propia, de una construcción teórica y práctica específica. Para Leite y Belchior, se trata de adecuar las normas, a través de su interpretación y adaptar todo el sistema jurídico a los nuevos instrumentos. Los autores van más allá y declaran que existe una necesidad de un Estado de derecho ambiental: «Al adoptar el paradigma del Estado de Derecho Ambiental es necesario un nuevo modo de ver el orden jurídico, con una previa comprensión diferenciada del intérprete, en la medida que la hermenéutica filosófica demuestra que el sentido a ser capturado de la norma jurídica es inagotable» ${ }^{23}$.

Los conflictos urbano-ambientales se muestran importantes a partir del momento en que generan otros derechos. Por este motivo, es primordial reconocerlos para que a partir de su reconocimiento surjan nuevos instrumentos jurídicos a fin de mediarlos y/o solucionarlos (vía acuerdos y superación de los conflictos). El reconocimiento de conflictos y de la permanente pluralidad es presupuesto necesario para la identificación de la vulnerabilidad social. Lo cual permite, de esta forma, alcanzar las condiciones de democracia, disenso y consenso. Se trata de un cambio en las estructuras - no solo jurídicas, sino culturales y de las prácticas sociales- Asimismo, crece el aparato jurídico desde las áreas del bioderecho, del derecho del consumidor y de los derechos humanos, entre otros. 
En esta nueva dinámica en la que «la acción social se entrelaza globalmente y las consecuencias de la intervención humana resultan crecientemente distantes y laberínticas», el derecho debe hacer frente a muchas cuestiones novedosas que se sustancian en otros tantos ámbitos jurídicos, como: «nuevas relaciones internacionales y revisión del derecho internacional, nuevas relaciones laborales y revisión del derecho del trabajo, derecho informático, derecho y bioética, derecho de los animales, derecho medioambiental, etcétera» ${ }^{24}$. En virtud de estos preceptos, se vislumbra nuevas formas de derecho, formas que contemplan las transformaciones de la sociedad y garantizan condiciones de vida de forma plural, justa e igualitaria.

La crisis ambiental es, también, una crisis social de las instituciones en las que se fundamenta la sociedad moderna. La crisis plantea una reconsideración de las prácticas institucionalizadas que la han producido y, por lo tanto, una reconsideración del papel de la ciencia en la sociedad. La idea esencial desarrollada por Beck ${ }^{25}$ es que el carácter reflexivo de la modernidad tardía (o posmodernidad) supone un cuestionamiento de las instituciones en las que se ha basado la modernidad. Para Oliveira Silva, el contexto contemporáneo es de injusticia ambiental a causa de la globalización:

En este contexto de injusticia ambiental instalada, tal vez sea esperado, o no, que el desafío de superación de una crisis ambiental sea asumido de diversas formas, una de ellas, la encabezada por los neoliberales que buscan instituir el pensamiento de que la propia naturaleza no admite fronteras, es decir, no ultrapasa el limite geográfico de los países, no se trata de un problema local, sino global $^{26}$.

A pesar de posiciones como esta, algunos autores no comparten estas impresiones y no asumen la existencia de una crisis ambiental. Coutinho $^{27}$, por ejemplo, critica la manera en que se suele abordar la crisis ambiental, afirmando que esta supuesta crisis está basada en concepciones aparentemente ingenuas de las relaciones entre medio

24 CAPella, Juan Rámon. Las sombras del sistema constitucional español. Madrid: Trotta, 2003, p. 191. 25 BECK, Ulrich. Ob. cit.

26 OlIVEIRA SILVA, José Irivaldo Alves de. «A questão ambiental institucionalizada: do local ao global». En Actas del XV Congresso Brasileiro de Direito Ambiental. Florestas, mudanças climáticas e serviços ecológicos. São Paulo, 2010, vol. I, p. 687.

27 «o Direito, no modo de produção capitalista, é um universo no qual se movimentam sujeitos jurídicos dotados de igualdade perante a lei na prática da liberdade para contratar. A norma jurídica que compõe esse Direito, por isso mesmo, é abstrata e geral. Esse mesmo Direito, assim, em um primeiro momento, viabiliza a fluência das relações de mercado e, mais tarde, com o advento das crises econômicas, o Estado capitalista assume um novo papel, intervindo na ordem social e o Direito, então, torna-se instrumento essencial na preservação dessa ordem. A final, a igualdade (perante a lei) e a universalidade das formas jurídicas (sujeição de todos ao domínio da lei) constituem componentes essenciais à estruturação do modo de produção capitalista" (COUTINHO, Ronaldo. "Direito e problemas urbano-ambientais: um roteiro de estudo". En AHMED, Flávio \& otros (orgs.). Curso de Direito Ambiental. Río de Janeiro: Lumen Júris, 2012, pp. 293-316, p. 293). 
ambiente y sociedad y que, en muchos y significativos casos, supone un riesgo y pone en peligro la propia supervivencia de la humanidad. Según el autor, esta suposición no identifica la crisis ambiental como una restructuración productiva del capitalismo e indica alternativas de solución centralizadas en la convicción de transformaciones expresivas del comportamiento individual con la adopción de una nueva ética, de orden ecológica y humanista, marcada por el altruismo y por el sentido de responsabilidad colectiva ${ }^{28}$.

Sin embargo, no existe duda de que el derecho debe, de forma eficaz, tutelar la naturaleza y los espacios propios de la ciudadanía. Conforme Duailibe y Belchior, delante de tanta liquidez e incertidumbres, el desafío de la ciencia hoy se apoya en la búsqueda de alguna solidez para definir el objeto de estudio. «Ao discutir a complexidade ambiental, extrai-se uma premissa jurídica sólida no auge da pós-modernidade e da sociedade de risco: se não existir um meio ambiente sadio, não há vida em suas mais varias formas» ${ }^{29}$.

Tanto el derecho ambiental como el derecho urbanístico son disciplinas autónomas, pero relativamente recientes dentro del derecho. Aún se encuentran en fase de maduración teórica. La autora brasileña Santilli desarrolla el tema bajo la óptica del socioambientalismo. Un concepto contemporáneo que intenta disminuir el abismo existente entre las cuestiones sociales y ambientales, construyendo puentes entre los movimientos sociales y las políticas públicas, con la finalidad de evitar la vulnerabilidad del hombre ante determinados hechos y circunstancias. La autora se refiere por ello a los «nuevos derechos socioambientales», caracterizados por el pluralismo jurídico; por el quiebre de los marcados paradigmas jurídicos que derivaban del excesivo apego al formalismo, a la falsa neutralidad política y científica; y por el excesivo énfasis en los derechos individuales de contenido patrimonial y contractualista ${ }^{30}$.

La cuestión ambiental actualmente puede ser utilizada como importante recurso ideológico, puesto que dicha crisis ambiental representa las deficiencias de un sistema social de producción y consumo (el sistema capitalista), cuya organización posiblemente termine con sus propios medios de reproducción. Así, el derecho ambiental puede ser interpretado como el filtro social capaz de regular toda esta dinámica de producción, con la finalidad de evitar que la actual situación social no decline o, aun, como un derecho que se origina para definir que los bienes y los recursos naturales también son bienes jurídicos, evitando que

28 COUTINHO, Ronaldo. "CCrise ambiental" e desenvolvimento insustentável: a mitologia da sustentabilidade e a utopia da humanização do capitalismo "selvagem"». Revista Praia Vermelha, XIX, 2 (2009), pp. 21-36, p. 22.

29 DuAlLIBE, Erika Pereira \& Germana Parente Neiva BELCHIOR. Ob. cit., p. 1547.

30 SANTILLI, Juliana. Socioambientalismo e novos direitos. Proteção jurídica à diversidade biológica e cultural. São Paulo: Editora Fundação Peirópolis, 2005, p. 57.

UNA REFLEXIÓN

SOBRE LOS

«NUEVOS»

DERECHOS.

PERSPECTIVASY DESAFÍOS EN EL

SIGLO XXI

A REFLECTION

UPONTHE

«NEW» RIGHTS.

PROSPECTS

AND CHALLENGES

IN THE

21ST CENTURY 
los mismos desaparezcan. De acuerdo con Jaria Manzano: «el derecho ambiental define el modelo de desarrollo de una sociedad, disciplinando el uso de la tecnología disponible para generar un grado determinado de bienestar» ${ }^{31}$.

En este sentido, es posible definir diferentes ámbitos de actuación del derecho ambiental. El reconocimiento del medio ambiente como objeto merecedor de tutela jurídica, así como la promoción de un consenso social sobre sus contornos, resultado del balance entre valores, bienes e intereses de diversas categorías, fruto de un proceso mediado por normas jurídicas. Al mismo tiempo, estos ámbitos producen resultados también materializados en forma de normas jurídicas ${ }^{32}$.

Para Faria ${ }^{33}$, el riesgo en este escenario jurídico es, por tanto, el que se genera con la aplicación de cualquier otro tipo de técnica: la ejecución de la técnica no alcanza por razones de imperfección mediata la proyección ideal, de manera que un mínimo desajuste en cualquier momento de la ejecución práctica puede desvirtuar el sentido original del desarrollo legislativo. Como en cualquier otra técnica, el aumento de complejidad en la misma hace aumentar igualmente el riesgo de resultados imprevistos. Aunque no se comparta la opinión de Faria, es un punto de vista a considerar. Puesta en crisis esta vinculación debido a —en los últimos tiempos- el aumento de la complejidad social, de las urgencias del derecho y de, por tanto, su propia complejidad interna, quedaría un solo motivo efectivo para el desarrollo del derecho: la adecuación y la adaptabilidad al entorno. De modo que el derecho se desarrolla conforme a sus propios precedentes inmediatos y tratando de adecuar la producción jurídica en vigor a la información obtenida del entorno social ${ }^{34}$.

Para terminar esta reflexión, no podrían ser más adecuadas las palabras de Waldman ${ }^{35}$, según quien, el cotejo con las contradicciones socioambientales que vivimos, necesariamente presupone el cotejo con el orden social que las origina. Como se observa, la problemática ambiental, en las ciudades o fuera de ellas, frente a la posmodernidad y la sociedad del riesgo, parece, como mínimo «alterar» las estructuras clásicas de la propia epistemología del derecho. Se revela, así, el reto de tornar eficaz la ciencia del derecho ${ }^{36}$.

31 JARIA MANZANO, Jordi. «El fundamento constitucional de los derechos de participación en materia ambiental de medio ambiente y su desarrollo en la ley 27/2006». En PIGRAU SOLÉ, Antoni (dir.). Acceso a la información, participación pública y acceso a la justicia en materia de medio ambiente: diez años del Convenio de Aarhus. Barcelona: Atelier, 2008, pp. 119-147, p. 132.

32 Cerski LaVRATtI, Paula. El derecho ambiental como instrumento de gestión del riesgo tecnológico. Tarragona: Universitat Rovira i Virgili, 2011, p. 80.

33 FARIA, José Eduardo. Ob. cit., p. 106.

34 PÉREZ González, Sérgio. «El Derecho en la sociedad global del riesgo». REDUR, 6 (2008), pp. 95-107, p. 102.

35 WALDMAN, Mauricio. Ecologia e lutas sociais no Brasil. São Paulo: Contexto, 1992, p. 64.

36 DuAILIBE, Erika Pereira \& Germana Parente Neiva BELCHIOR. Ob. cit., p. 1553. 


\section{CONSIDERACIONES FINALES}

La Posmodernidad es el período sociohistórico posterior a la modernidad, como el nombre así lo indica, sumergido en la transición advenida de la crisis de los paradigmas de la modernidad. Este período absorbió todos los riesgos involucrados en este proceso de transición, lo cual llevó a que se denomine a la sociedad actual la sociedad del riesgo. Frente a tantas incertidumbres de conceptos, de prácticas y de paradigmas, de transformaciones y de creación de otras referencias, no sería exagerado afirmar que hoy, en el siglo XXI, es la sociedad del riesgo la que está en crisis. Si el riesgo es resultado de los avances de la era industrial, de la modernización de la información y del aumento de la complejidad de los procesos de toma de decisiones, es oportuno analizarlos en una dimensión futura, razón por la cual se hace necesaria la consideración de sus consecuencias sociales.

En tiempos posmodernos, de rompimiento de paradigmas y de transformaciones en la estructura del derecho, la falta de confianza de la sociedad en los institutos jurídicos no puede ser algo natural y aceptable. Se requiere, por tanto, instrumentos eficaces y urgentes que subsanen esta carencia. Por eso, la insistencia en que exista una adaptación jurídica para salvaguardar al hombre de las vulnerabilidades que le asolan en el siglo XXI. Mediante tantas ambigüedades, la sociedad posmoderna no estaría respondiendo a las demandas sociales de la globalización y de consumo de manera satisfactoria, en este sentido, se manifiestan las injusticias sociales y ambientales del mundo. No obstante, es significativo que la nueva ciudadanía incluya el proceso de creación de «nuevos» Derechos y que surjan prácticas reales, como por ejemplo el derecho de los pueblos indígenas a la diversidad cultural, a la vivienda y, sobre todo, el derecho a la sostenibilidad.

Para concluir, se asevera que discutir la naturaleza y el alcance de los derechos e intereses difusos tanto en el ámbito urbano como en el ambiental es fundamental y urgente. Asimismo, es inminente evaluar en qué medida los intereses difusos son intereses universales, o por lo menos, intereses de la mayoría. 